\title{
MARC DÉCIMO, Des fous et des hommes avant l'art brut
}

\section{Sara Arena}

\section{OpenEdition \\ Journals}

\section{Edizione digitale}

URL: http://journals.openedition.org/studifrancesi/16642

DOI: 10.4000/studifrancesi. 16642

ISSN: 2421-5856

\section{Editore}

Rosenberg \& Sellier

\section{Edizione cartacea}

Data di pubblicazione: 1 juillet 2019

Paginazione: 186

ISSN: 0039-2944

\section{Notizia bibliografica digitale}

Sara Arena, «MARC DÉcImo, Des fous et des hommes avant l'art brut», Studi Francesi [Online], 187 (LXIII | I) | 2019, online dal 01 juillet 2019, consultato il 25 janvier 2021. URL: http://journals.openedition.org/ studifrancesi/16642 ; DOI: https://doi.org/10.4000/studifrancesi.16642

Questo documento è stato generato automaticamente il 25 janvier 2021.

\section{(c) (†)}

Studi Francesi è distribuita con Licenza Creative Commons Attribuzione - Non commerciale - Non opere derivate 4.0 Internazionale. 


\title{
MARC DÉCIMO, Des fous et des hommes avant l'art brut
}

\author{
Sara Arena
}

\section{NOTIZIA}

MARC DÉCIMO, Des fous et des hommes avant l'art brut, suivi de l'édition critique et augmentée de MARCEL RÉJA, L'art chez les fous. Le dessin, la prose, la poésie (1907) et des textes de Benjamin Pailhas, Joseph Capgras, Maurice Ducosté, Ludovic Marchand et Georges Petit, Dijon, Les presses du réel, 2017, «Les Hétéroclites», 470 pp.

1 Un volume corposo e composito propone l'edizione critica di L'art chez les fous. Le dessin, la prose, la poésie, del 1907, opera del medico, scrittore, poeta e storico dell'arte Marcel Réja (pp. 183-384).

2 Nel saggio che precede l'edizione, Marc Décimo, docente di storia dell'arte contemporanea, mette in luce, attraverso citazioni di saggi e articoli dell'epoca e un lavoro di puntuale ricostruzione storica, l'interesse crescente per i prodotti artistici dei malati mentali - disegni, sculture, testi - dalla Belle Époque fino alla teorizzazione dell'art brut da parte di Jean Dubuffet nel 1948 (pp. 11-182).

Il testo introduttivo mostra come l'arte "dei folli", spesso associata a quella dei "selvaggi", sia stata oggetto di studio e ricerca per molteplici ragioni, mediche ed estetiche al contempo, e abbia suscitato interrogativi fondamentali intorno a questioni essenziali come i limiti della normalità, la nozione stessa di follia e i suoi rapporti con l'arte, il genio, la creazione.

4 Nella prima parte del secolo scorso, la curiosità per le espressioni artistiche degli aliénés, testimoniata anche da alcune discusse esposizioni, si colloca infatti all'interno di un più ampio interesse per le manifestazioni estetiche dell'“altro" inteso in tutte le sue accezioni: arte infantile, popolare, primitiva, esotica; si intreccia alla nascita e alla parabola delle Avanguardie; incrocia la Grande Storia e le contrapposizioni ideologiche del tempo, a tal punto che le prime mostre di opere di malati psichiatrici suscitano 
accesi dibattiti e polemiche sulle riviste del tempo, puntualmente documentati nel saggio di Décimo. L'accoglienza riservata dal nazismo alle opere degli autori d'avanguardia così come a quelle degli aliénés la dice lunga su alcune delle poste in gioco in tali contrapposizioni.

5 Merito di un certo numero di medici e critici del tempo, citati da Décimo in una ricostruzione del contesto non solo francese, è dunque quello di aver saputo cogliere nei disegni, nelle sculture e nei testi dei pazienti l'elemento di fondamentale interesse che essi contenevano, sia dal punto di vista scientifico - possibilità di indagare la patologia attraverso il testo o l'immagine, possibilità di impiegare utilmente il tempo del paziente - sia da quello estetico: riconoscimento del valore artistico, ove presente, e riflessione sul concetto stesso di ispirazione e di bellezza.

6 Marcel Réja - il cui testo, già riproposto in alcune pubblicazioni nel corso del Novecento, è qui fornito in un'edizione filologicamente curata, accompagnata da un corredo di note e da una successione di immagini più ricca e rispettosa delle esigenze di lettura - fu per l'appunto tra gli specialisti dell'epoca che con maggiore lucidità intuirono l'importanza di tali manifestazioni e la necessità di porre confini meno rigidi tra norma e follia. "Aliéniste éclairé" (p. 7), Réja affronta dunque nel suo testo, capitolo per capitolo, «Les dessins des fous» (pp. 193-265), i «Dessins d'enfants et de sauvages» (pp. 267-290), «La poésie» (pp. 291-335) e «La prose» (pp. 336-380).

7 Da ultimo, una piccola sezione di «Annexes» (pp. 384-443) raccoglie alcuni testi di Benjamin Pailhas, Joseph Capgras, Maurice Ducosté, Ludovic Marchand et Georges Petit, compresi tra il 1908 e il 1912.

8 Da segnalare, nel volume, il valore della componente iconografica; le numerosissime immagini che accompagnano non solo l'edizione critica di L'art chez les fous, ma anche il saggio introduttivo permettono infatti al lettore di passeggiare idealmente attraverso una ricca galleria di opere della più varia natura e del più diverso valore. 